\title{
Some determinant factors of antimicrobial susceptibility pattern of plant extracts
}

\author{
Sylvester Chibueze Izah* \\ Department of Biological Sciences, Faculty of Science, Niger Delta University, Wilberforce Island, Bayelsa State, Nigeria
}

\begin{abstract}
Plants are major active ingredients used for the treatment of several human diseases by traditional medicine practitioners in many regions of the world especially in developing countries. Plants are among the major feedstocks that have been researched upon for development of new antibiotics. Plants are known to contain several bioactive/ phytochemical constituents they may be responsible for their medicinal properties. Studies have shown that plant extract that are susceptible to a specific microbe may not be the same in another related study. Hence, this study reviews the factors that determine the susceptibility pattern of plant extracts. The study found that environmental factors ( $\mathrm{pH}$ of the medium, temperature, water activity, oxygen and nutrient availability), choice of solvent, source of the organisms, biochemistry, physiology, metabolism and adaptation strategies of the microbes, plant species, biochemistry, age and parts, concentration of the plant extract and period of extraction. Hence there is the need for research to consider these determinant factors during antimicrobial susceptibility studies.
\end{abstract}

\section{Introduction}

Microorganisms play essential role in human and its activities. This is because some species of microbes are extreme useful to human, while several other species are detrimental which could lead to disease conditions if not adequately managed. Most microbes that that have adverse effect to human mainly belong to the group of virus, bacteria and fungi. While the microbes that play essential role in human are mainly some species of bacteria and fungi. For instance, the yeast, Saccharomyces cerevisiae play essential role in biodegradation of effluents and useful in feed and food production especially in bakery [16]. Another bacterium, Lactobacillus bulgaricus is essential in human diet because of its role in yoghurt production. These two microbes are typical example of grass organisms that have implicated with food safety [7].

Several species of pathogenic microbes are essential in maintenance of certain body parts of human at certain density. Some of these microbes have also been reported to cause infection in different part of the human body. For instance, in wound infection, several diversity of bacteria and their occurrence rate have been reported including Staphylococcus aureus (28.2\%), Pseudomonas aeruginosa (17.9\%), Streptococcus species (10.3\%), Klebsiella species (14.1\%), Enterobacter species (11.5\%), Escherichia coli (10.3\%) and Proteus species $(7.7 \%)$, Staphylococcus aureus (35.8\%), Coagulase negative Staphylococcui (31.1\%), Streptococcus pyogene (4.6\%), Proteus vulgaris (6.0\%), Proteus mirabilis (8.6\%), Klebsiella species (3.3\%), Pseudomonas species (6.0\%), Escherichia coli (3.3\%) and Citrobacter freundii (1.3\%), Staphylococcus aureus (57.0\%), Proteus species (16.4\%), Pseudomonas aeruginosa (15.2\%), Escherichia coli (14.5\%), Klebsiella species (12.7\%), Coliforms (1.8\%), a-haemolytic streptococcus (1.2\%) [8-10]. Staphylococcus aureus (38\%), Pseudomonas aeruginosa (18.7\%), Klebsiella species (17\%), Escherichia coli (10.6\%), Proteus species (7.4\%), Staphylococcus epidermidis (4.4\%), Streptococcus species (1.6\%), Enterococcus faecalis (1.4\%) [11], Pseudomonas species (29.9\%), Staphylococcus aureus (27.5\%), Klebsiella species (18.5\%), Proteus species (15.1\%), Escherichia coli (7\%), Streptococci (2\%), and Enterococci (0.3\%) in different region of Nigeria [12]. These groups of bacterial are the most commonly studied organisms for antimicrobial susceptibility pattern using plant extract.

Several species of plant have demonstrated medicinal potentials to different disease conditions. Authors have severally reported that medicinal plants are plants whose different parts (flower, leaves, roots, stem-bark, flower, fruit) have therapeutic properties against several kind of diseases [13-23]. From time immemorial herbs have been variously used as an active ingredient for the treatment of some diseases especially in rural areas in many developing countries. In addition, traditional medicine practitioners use herbs to cure several diseases. Some of the herbs potentials have been validated scientifically, while several others need to be further studied.

Some of the common antibiotics in use include Ampiclox, Erythromycin, Flagyl (Clotrimazole), Ampicillin etc (oral application), Gentamycin, Streptomycin, procaine penicillin etc. (intramuscular application) and procaine penicillin, streptomycin, Cicatrin etc. (topical application). Due to microbial resistance against some known antibiotics, plants have emerged as credible substitute/alternative. To this regards several plants specimens have been widely studied [14-25].

The antimicrobial susceptibility pattern of plant extract varies based on different factors for the same plant and organisms. Hence this present study focused on the factors that could influence the susceptibility pattern of plant extract.

${ }^{*}$ Correspondence to: Sylvester Chibueze Izah, Department of Biological Sciences, Faculty of Science, Niger Delta University, Wilberforce Island, Bayelsa State, Nigeria, Tel: +2347030192466, E-mail: chivestizah@gmail.com

Key words: Antimicrobial, Disease condition, Microbial pathogens, Plant extracts Received: July 12, 2018; Accepted: July 30, 2018; Published: August 05, 2018 


\section{Antimicrobial resistance and role of medicinal plants in managing diseases caused by microorganisms}

Antimicrobial resistance is among the main threats facing humanity despites the progress made in the field of herbal medicine and pharmaceutical microbiology and chemistry. Several groups of antibiotics are now becoming resistance to some microbial pathogens. For instance, Anyanwu and Okoye [26] reported that rapid spread of multi- and pan-drug-resistant organisms including vancomycin-, methicillin-, extended-spectrum $\beta$-lactam-, carbapenem- and colistin-resistant organisms is a major global problem. The impacts of antimicrobial resistance are horrible about health concern and economic scale [26]. Valle Jr et al. [27] opinioned that infection complications are contributing to mortality and morbidity among hospitalized patients. Misuse of antibiotics and adverse effects of known antibiotics on some group of individuals is also a contributing challenge in the field of antibiotics production. Probably due to these challenges, research on the development of new, effective, and safe antimicrobials is on the rise [26].

Plants have emerged a suitable source of new antimicrobial. As such, several studies have been carried out about antimicrobial, phytochemical/bioactive composition, essential oil constituent of some plants for its possible utilization in medicine. Nurmilatina and Prabawa [28] reported that Cassia alata leave extract contain secondary metabolite compounds including alkaloids, saponin, tannins, phenolic, triterpenoids, quercetin and steroids. Timothy et al. [29] reported the presence of saponins, terpenes, flavonoids, reducing sugar and glycoside in both ethanolic and aqueous extract, and anthraquinones in only ethanolic extract of Cassia alata. Alalor et al. [30] reported that Cassia alata is rich in anthraquinones and polyphenols. Epidi et al. [21] reported that Alstonia boonei tissues contain tannins, saponins, flavonoids, cardiac glycosides, alkaloids, and phlobatanins. Epidi et al. [22] also reported that Vitex grandifolia also contain tannins, saponins, flavonoids, cardiac glycosides, alkaloids, and phlobatanins. Studies have reported the presence of different phytochemical in several plant species. Some of the phytochemical identified in the plant have been revealed to have antimicrobial potentials including alkaloids, flavonoids [18,21,22,25,31-33]. Like other medicinal potentials of tannins, it's also used for the treatment of wounds, varicose ulcers, hemorrhoids, frostbite and burns [22,25,33-35]. As such, authors have variously referred medicinal plants as plants that whose one or more parts have healing properties [13-22,25,26]. Traditional medicine practitioners also use plant as active ingredients for preparing decoctions against some specific disease condition.

\section{Determinant factors of antimicrobial susceptibility of plants extracts}

Several factors that determine the antimicrobial susceptibility pattern of plant extracts. Some of these factors include environmental factors, choice of solvent, source of the organisms, biochemistry, physiology, metabolism and adaptation strategies of the microbes, plant species, biochemistry, age and parts, concentration of the plant extract and period of extraction.

\section{Choice of extraction solvent}

Antimicrobial potentials of plants using solvents for extraction have been widely reported in literature. Several solvents have been widely used for extracting bioactive ingredients of plants. Some of the common solvents used for extraction of plant materials include alcohols (methanol and ethanol), chloroform, hexane, water etc. [14-22]. The concentration of phytochemicals and antimicrobial susceptibility pattern varying according to choose of solvent $[21,22,36]$. Different plants have demonstrated that varying effects of solvent. For instance, Epidi et al. [21] reported that zone of inhibition of Alstonia boonei extract were in the order of; aqueous $<$ hexane $<$ methanol<ethanol. Epidi et al. [22] also reported that zone of inhibition based on solvent type to be in the order; aqueous $<$ hexane $<$ methanol $<$ ethanol for Vitex grandifolia. The superiority of ethanolic extract of plant materials have been validated by authors using different plants including Alstonia boonei, Alligator pepper, Alchornea cordifolia [18,32,34,37]. Timothy et al. $[29,38]$ also reported that ethanolic extract have superior efficacy compare to other extracts. The differences in the choice of solvent could be due to their polarity.

\section{Concentration of the plant extract}

Several studies have been carried out with regard to antimicrobial activities of plant extracts on individual plant parts, synergy of plants parts and combination of different plants species [16-22,39]. Authors have variously used different concentration of plant extract in antimicrobial susceptibility testing, and results have suggested that different plant yield have varying zone of inhibition. Studies have suggested that combination of different parts of a plant, and/or two or more plant species confers varying effect on microorganisms $[16,17,21,22,23,39]$. Apparent superior zone of inhibition has been reported in synergistic effect of methanolic leaf extracts of Vernonia amygdalina and Ocimum gratissimum methanolic leaf extract of Cymbopogon citratus and rhizome of Zingiber officinale, and acetone extracts of Garcinia kola and Buchholzia coriacea $[16,17,20]$. Also, within individual plant the zone of inhibition reflects in the concentration of extracts used for the study. Kigigha et al. $[18,20]$, Izah et al. $[14,16]$ reported that zone of inhibition declines as the concentration of the extract decreases.

\section{Age of the plant}

Several species of plants are found in nearly all the regions of the world [39]. The availability of specific species depends on the prevailing climatic, soil and environmental conditions of the area [39]. The age of the plant tends to determine the concentration of bioactive ingredients that is available, which may play essential role in the susceptibility pattern [13-16,19,20]. Different parts of plants have been widely studied for antimicrobial potentials as well and the results showed that different plant parts have varying efficacy on microbial isolates $[16,19,21,22]$.

\section{Period of extraction}

Authors have variously reported different extraction period of plant materials used for susceptibility testing. Most period of plant extraction that is commonly reported in literature is $24-72$ hours [13-16,18$22,36]$. The period of extracting may play essential role in determining the concentration of the extract which may in turn influence the zone of inhibition.

\section{Source of the microorganisms}

Microbes are ubiquitous and tend to use different adaptation mechanisms for survival in a environment. Microbes obtained from different environmental source and human body parts have been widely tested for susceptibility to plant extract. Within the human body, microbes isolated from would infection have been tested for antimicrobial potentials [36]. Typically, wound is generally described as loss of skin integrity with regard to structure $[10,40]$. The skin has several functions including control the population of microbes that 
reside or thrive in the skin especially the pathogenic ones. Exposure of subcutaneous tissue due to injury offers a suitable environment for microbes to thrive. This environment viz: moist, warm, and nutrition is conducive for microbial colonization, proliferation, and can cause damage to the host tissues $[8,41]$. Wound is usually colonized by several diversity of pathogen depending on the duration, antibiotics in use and hygienic nature of the wounds. As such the sensitivity pattern of plant extract depends on these factors (viz: antibiotics in use and duration of the microbes in the wound infection).

\section{Metabolism and biochemistry of the microorganisms}

Microbial metabolism is the process through microorganisms derives their nutrient that may produce energy needed for growth and proliferation [42]. Though several types of microbes have been studied for susceptibility pattern using plant extracts. But depending on the type of microbes under consideration, this is because most microorganisms have different metabolic characteristics. Different microbes that belong to various types of microbial metabolisms have been studied for susceptibility by plant extracts. But among them the group of chemoorganoheterotrophs (organism that obtain carbon, energy, and reducing equivalents needed for several biosynthetic reactions from organic compounds) are the commonly studied for susceptibility testing [42]. Some of these bacteria that belong to this class are Escherichia coli (gram negative bacteria) and Bacillus species (gram positive species) [43]. Some other means through which microorganisms derive carbon is from the fixation of carbon dioxide and energy through oxidation of inorganic compounds (chemolithoautotrophs). Examples of microorganisms that undergo this type of metabolism iron and sulphur oxidising bacteria and nitrifying bacteria. Microbes also obtain energy from light and carbon from the fixation of carbon dioxide, using reducing equivalents from inorganic compounds (photolithoautotrophs), microbes that only obtain energy through oxidation of inorganic compounds (chemolithoheterotrophs), microbes that obtain energy from light processes, carbon and reducing equivalents required for biosynthetic of several reactions from organic compounds (photoorganotrophs) [42]. The type of metabolism utilized by the microorganisms under study may play important role in the susceptibility pattern. Bacteria specifically have different cell wall characteristics, and this could also contribute to the anti-microbial susceptibility profile of plant extracts.

\section{Adaptation strategies of the microorganisms}

Due to the nature of microorganism they have several techniques through which they survive in their environment. By their nature microorganisms are ubiquitous and have the tendency to survive in varying condition depending on their biochemical composition. Some microbes have the tendency to proliferate faster compare to others. Many microbes have the potentials to produce enzymes under certain condition. For instance, Ohimain et al. [43] reported that Staphylococcus aureus, Bacillus and Pseudomonas species (bacteria), Aspergillus niger, Penicillium, Fusarium, Mucor and Candida species (fungi) isolated from palm oil mill effluents can be used to produce amylase. Arotupin [44] also reported that Aerococcus viridens, Bacillus subtilis, Bacillus species, Corynebacterium manihot, Lactbacillus acidophilus, Aspergillus niger, Articulospora inflate, Geotrichum candidum, candida utilis, Saccharomyces exguus isolated from cassava waste water are amylase producing microorganisms. Other adaptation strategies such as molecular, metabolic and physiological processes and environmental tolerance influence the sensitivity of microorganisms to plant extracts.

\section{Environmental factor of the plant extracted medium and incubation period}

Microorganisms have the tendency to grow in different environmental conditions. Some of the notable environmental parameters to may affect the growth rate of microbes include $\mathrm{pH}$ of the medium, temperature, water activity (moisture), osmotic pressure, oxygen availability and nutrient composition. Different organisms are known to grow under varying acidity or alkalinity level depending on the tolerance level. Typically, microorganisms grow in different environmental condition including low temperature optima (psychrophiles), mid-range temperature optima-which is mainly required by warm blooded animals, terrestrial and aquatic environments in temperate and tropical region of the world (mesophiles), high temperature optima unusually meant for hot environments (thermophiles) and very high temperature optima which is usually found in the hot springs, geysers, deep sea hydrothermal vents (hyperthermophiles). Most microbes that cause human diseases that have been widely studied are mainly mesophiles. Some microorganisms are known to thrive in environment containing oxygen while several others do grow under anaerobic condition. Nutrients are also essential in susceptibility testing studies. This is because microbes need it for growth and proliferation. Water activity could also influence the susceptibility pattern of microbes.

\section{Conclusion}

Due to the challenges associated with drug resistance, studies have been intensified in the field of herbal medicine, pharmaceutical chemistry and microbiology. Plants have been projected as an effective and sustainable raw material for the production of new antibiotics. This study reviews the determinant factors of susceptibility profile of plant extract and the study found environmental factors, solvent type, source, characteristics and adaptation strategies of the organisms, biochemical constituents of the plant species, concentration of the plant extract and period of extraction. Therefore, there is the need for research to consider this factor during antimicrobial studies.

\section{References}

1. Izah SC, Bassey SE, Ohimain EI (2017) Changes in the treatment of some physicochemical properties of cassava mill effluents using Saccharomyces cerevisiae. Toxic 5: 28 .

2. Izah SC, Bassey SE, Ohimain EI (2017) Removal of Heavy Metals in Cassava Mill Effluents with Saccharomyces cerevisiae isolated from Palm Wine. MOJ Toxicol 3: 00057.

3. Izah SC, Bassey SE, Ohimain EI (2017) Amino acid and proximate composition of Saccharomyces cerevisiae biomass cultivated in Cassava mill effluents. Mol Microbiol Res 7: 20-29.

4. Izah SC, Bassey SE, Ohimain EI (2017) Cyanide and Macro-Nutrients Content of Saccharomyces cerevisiae Biomass Cultured in Cassava Mill Effluents. Int J Microbiol Biotechnol 2: 176-180.

5. Izah SC, Bassey SE, and Ohimain EI (2017) Assessment of Some Selected Heavy Metals in Saccharomyces cerevisiae Biomass Produced from Cassava Mill Effluents. EC Microbiol 12: 213-223.

6. Izah SC (2017). Potentials of Yeast Biomass Production from Food Processing Wastes Effluents. EC Nutrition 8: 72-74.

7. Izah SC (2018) Estimation of Saccharomyces cerevisiae Biomass Cultured in Cassava Mill Effluents. Environ Anal Eco stud 2: EAES.000547.

8. Obi CN (2015) Isolation and sensitivity pattern of bacterial isolates of wound infections from patients of Federal Medical Centre, Umuahia. Abia State. Int J Curr Microbiol App Sci 4: 371-379.

9. Muhammad UK, Adamu TM, Binji Z, Isa MA (2014) Prevalence of pathogenic bacteria isolated from surgical site and wound infection among patients admitted in some selected hospitals in Sokoto metropolis, Nigeria. Int J Environment 3: 89-103. 
10. Gadzama GB, Zailani SB, Abubakar SB, Bakari AA (2007). Bacterial pathogens associated with wound infections At the University of Maiduguri teaching hospital, Maiduguri, Nigeria. Kanem J Med Sci 1: 26-28.

11. Okesola AO, Kehinde AO (2008) Bacteriology of non-surgical wound infections in Ibadan, Nigeria. Afr J Med Med Sci 37: 261-264. [Crossref]

12. Thanni LOA, Osinupebi OA, Deji-Agboola M (2003) Prevalence of bacterial pathogens in infected wounds in a tertiary hospital, 1995-2001: any change in trend? J Natl Med Assoc 95: 1189 - 1195. [Croosref]

13. Izah SC, Uhunmwangho EJ, Eledo BO (2018) Medicinal potentials of Buchholzia coriacea (wonderful kola). Medicinal Plant Research 8: 27-43.

14. Izah SC, Zige DV, Alagoa KJ, Uhunmwangho EJ, Iyamu AO (2018). Antibacterial Efficacy of Aqueous Extract of Myristica fragrans (Common Nutmeg). EC Pharmacol Toxicol 6(4): 291-295.

15. Izah SC, Uhunmwangho EJ, Dunga KE, Kigigha LT (2018) Synergy of methanolic leave and stem-back extract of Anacardium occidentale 1. (cashew) against some enteric and superficial bacteria pathogens. MOJ Toxicol 4: 209-211.

16. Izah SC, Uhunmwangho EJ, Etim NG (2018). Antibacterial and synergistic potency of methanolic leaf extracts of Vernonia amygdalina L. and Ocimum gratissimum L. J of Basic Pharmacol \& Toxicol 2: 8-12.

17. Izah SC, Aseibai ER (2018) Antibacterial and Synergistic activities of methanolic leaf extract of Lemon grass (Cymbopogon citratus) and rhizome of Ginger (Zingiber officinale) against Escherichia coli, Staphylococcus aureus and Bacillus species. ACTA Microbiol 1: 26-30.

18. Kigigha LT, Izah SC, Ehizibue M (2015) Activities of Aframomum melegueta Seed Against Escherichia coli, S. aureus and Bacillus species. Point Journal of Botany and Microbiology Research 1: 23-29.

19. Kigigha LT, Biye SE, Izah SC (2016) Phytochemical and antibacterial activities of Musanga cecropioides tissues against Escherichia coli, Pseudomonas aeruginosa Staphylococcus aureus, Proteus and Bacillus species. Int J Applied Res \& Technol 5: 100-107.

20. Kigigha LT, Selekere RE, Izah SC (2018). Antibacterial and synergistic efficacy of acetone extracts of Garcinia kola (Bitter kola) and Buchholzia coriacea (Wonderful kola). J of Basic Pharmacol \& Toxicol 2: 13-17.

21. Epidi JO, Izah SC, Ohimain EI (2016) Antibacterial and synergistic efficacy of extracts of Alstonia boonei tissues. British Journal of Applied Science 1: 21-26.

22. Epidi JO, Izah SC, Ohimain EI, Epidi TT (2016) Antibacterial and synergistic potency of tissues of Vitex grandifolia. Biotechnol Res 2: 69-76.

23. Kigigha LT, Kalunta CG (2017). Antimicrobial efficacy of leaf extracts of Piper nigrum against Escherichia coli, Staphylococcus aureus and Candida albicans. Journal of Basic Pharmacology and Toxicology, 1:32-36.

24. Kalunta CG (2017) Antimicrobial effect of different seed extracts of Piper nigrum against Escherichia coli, Staphylococcus aureus and Candida albican. Biotechnol Res 3: 71-76.

25. Kigigha LT, Zige DV (2013) Activity of Chromolaena Odorata on enteric and superficial etiologic bacterial agents. Am J Res Commun 1: 266-276.

26. Anyanwu MU and Okoye RC (2017). Antimicrobial activity of Nigerian medicinal plants. J Intercult Ethnopharmacol 6: 240-259.
27. Valle Jr. DL, Andrade JI, Puzon JJM, Cabrera EC, Rivera WL (2015) Antibacteria activities of ethanol extracts of Philippine medicinal plants against multidrug-resistant bacteria. Asian Pac J Trop Biomed 5: 532-540.

28. Nurmilatina, Prabawa DGP (2017) Utilization of Ethanol Extract of Gulinggang (Cassia alata Linn) Leaves as Antifungal in Body Soap Bar. Jurnal Riset Industri Hasil Hutan 9: 57 -64.

29. Timothy SY, Lamu FW, Roda AS, Adati RG, Maspalma ID, et al. (2012) Acute toxicity, phytochemistry and antibacterial activity of aqueous and ethanolic leaf extracts of Cassia alata linn. Int Res J Pharm 3: 73-76.

30. Alalor CA, Igwilo CI, Jeroh E (2012) Evaluation of the Antibacterial Properties of Aqueous and Methanol Extracts of Cassia alata. J Pharm \& Allied Health Sci 2: 40-46.

31. Agu GC, Thomas BT (2012). Antibacterial Activities of Ethanol and Aqueous Extracts of Five Nigerian Medicinal Plants on Some Wound Pathogens. Nature and Science 10: $78-84$.

32. Opoku F and Akoto O (2015) Antimicrobial and Phytochemical Properties of Alstonia Boonei Extracts. Org Chem Curr Res 4.

33. Osuntokun OT and Oluwafoise BO (2015). Phytochemical screening of ten Nigerian medicinal plants. Int J Multidiscip Res Dev 2: 390-396.

34. Doherty VF, Olaniran OO and Kanife UC (2010). Antimicrobial activities of Aframomum Melegueta (Alligator pepper). Int J Biol 2: 126-131

35. Okwu DE, Okwu ME (2004). Chemical composition of Spondias mombia Linn plan parts. Journal of Sustain Agricultural Environment 6: 140-147.

36. Uhunmwangho EJ, Nwadike I, Iyamu AO (2017) Antibacterial activities of leave extract of siam plant (Chromolena odorata) and craw plant (Cassia alata) combined, on bacterial isolates from wound in Ekpoma. Int J Med Sci \& Pharm Res 1: 01-10.

37. Kigigha LT, Atuzie MN (2012) Assessment of traditional medicinal application of Alchornea cordifolia. African Journal of Biotechnology 11: 2083-2086.

38. Timothy SY, Wazis CH, Adati RG, Maspalma ID (2012) Antifungal activity of aqueous and ethanolic leaf extracts of Cassia alata linn. Journal of Applied Pharmaceutical Science 2:182-185.

39. Epidi JO (2016) Antibacterial and synergistic studies of tissue extracts of Alstonia boonei De Wild and Vitex grandifolia Gürke. MSc thesis submitted to Post graduate school, Niger Delta University, Wilberforce Island, Nigeria. 98.

40. Iregbu KC, Uwaezuoke NS, Nwajiobi-Princewill IP, Eze SO, Medugu N, et al (2013) A profile of wound infections in national hospital Abuja. African J Clin \& Exp Microbiol 14: 160-163.

41. Mama M, Abdissa A, Sewunet T (2014) Antimicrobial susceptibility pattern of bacterial isolates from wound infection and their sensitivity to alternative topical agents at Jimma University Specialized Hospital, South-West Ethiopia. Ann Clin Microbiol Antimicrob 13: 14. [Crossref]

42. Wikipedia (2018) Microbial metabolism. https://en.wikipedia.org/wiki/Microbial metabolism. Accessed July $5^{\text {th }}, 2018$.

43. Ohimain EI, Izah SC, Jenakumo N (2013) Physicochemical and microbial screening of palm oil mill effluents for amylase production. Greener Journal of Biological Sciences 3(8): $314-325$.

44. Arotupin DJ (2007) Evaluation of microorganisms from cassava waste water for production of amylase and cellulase. Research Journal of Microbiology 2(5): 475 - 480.

Copyright: (C2018 Izah SC. This is an open-access article distributed under the terms of the Creative Commons Attribution License, which permits unrestricted use, distribution, and reproduction in any medium, provided the original author and source are credited. 